\title{
A Rare Case of Transdermal Methanol Intoxication
}

\author{
Ulaş Karaoğlu' , Aydın Sarıhan², Mehtap Bulut ${ }^{1}$ \\ 'Department of Emergency Medicine, İstanbul Medipol University School of Medicine, İstanbul, Turkey \\ 2Department of Emergency Medicine, Manisa State Hospital, Manisa, Turkey
}

Cite this article as: Karaoğlu U, Sarıhan A, Bulut M. A Rare Case of Transdermal Methanol Intoxication. J Emerg Med Case Rep 2017; 8: 52-4.

\begin{abstract}
Introduction: Methanol is a clear, colorless, and highly toxic liquid which is a common component of antifreeze solutions, paints, varnishes, gasoline mixtures, and various solvents. Even though methanol is used only in industry, when ingested accidentally or for suicide it may cause methanol intoxication which has high mortality rates. Methanol intoxication is generally seen after accidental or suicidal oral intake. Methanol can be absorbed by inhalation or through the skin, which rarely leads to clinical toxicity.

Case Report: Herein, we present a case of methanol intoxication associated with absorption through the skin which is one of the rare ways of poisoning. We aim to emphasize that methanol intoxication rarely occurs after dermal exposure.

Conclusion: Emergency department physicians must consider methanol intoxication in patients of high anion gap metabolic acidosis with visual symptoms even if the patient has no history of oral intake.
\end{abstract}

Keywords: Methanol intoxication, transdermal, denatured alcohol

Received: 31.07.2016 Accepted: 14.10.2016 Available Online Date: 30.11.2016

\section{Introduction}

Denatured alcohol, also called methylated spirit, is a blue/purple colored and methanol containing liquid which is used as a solvent for cleaning purposes or as a fuel for alcohol burners and camping stoves. Methanol is a clear, colorless, and highly toxic liquid which is a common component of antifreeze solutions, paints, varnishes, gasoline mixtures and various solvents. Even though methanol is used only in industry, when ingested accidentally or for suicide it may cause methanol intoxication which has high mortality rates.

Methanol intoxication is generally seen after accidental or suicidal oral intake, and although rare, some cases of poisoning have been reported due to inhalation or transdermal absorption (1-4). In this case report we present a case of transdermal methanol intoxication and aim to emphasize that methanol intoxication rarely occurs after dermal exposure, and to draw attention to the possible serious results of alternative medicine practices that can be fatal.

\section{Case Report}

A 52-year-old male patient came to the emergency department (ED) with weakness, vomiting, and loss of vision. A day earlier, he wore a spirit-soaked sweater because of cold complaints. The patient said that this odd advice came from a close friend. After about four hours, he began to vomit. He was admitted to the ED of a state hospital where he was given only antiemetic therapy. Then he was discharged to go home due to a relief of symptoms. However, his symptoms started again and he was admitted to our ED with blurred vision.

This study was presented at the $4^{\text {th }}$ Eurasian Congress on Emergency Medicine, 13-16 November 2014, Antalya, Turkey

Address for Correspondence:

Mehtap Bulut, Department of Emergency Medicine, Istanbul Medipol University School of Medicine, İstanbul, Turkey

E-mail: mbulut94@yahoo.com

oCopyright 2017 by Emergency Physicians Association of Turkey - Available online at www.jemcr.org 
The patient's vital signs were Blood Pressure (BP): 120/75 mmHg, SpO2: 99\%, and pulse: 108 bpm. Upon neurological examination, the patient was conscious, cooperative, and well-orientated with a Glasgow Coma Score of 15, and he could count fingers from a 1 meter distance but he said is sight was blurry. He had normoactive deep tendon reflexes and he had no pathological reflexes. The remainder of the physical examination was unremarkable. The initial laboratory test results were as follows: hemoglobin $17.6 \mathrm{~g} / \mathrm{dL}$, hematocrit 53\%, leukocytes 16,800 cells $/ \mathrm{mm}^{3}$ (14,700 neutrophils and 1,200 lymphocytes), platelets 372,000 cells $/ \mathrm{mm}^{3}$, glucose 97.5 $\mathrm{mg} / \mathrm{dL}$, urea $55.3 \mathrm{mg} / \mathrm{dL}$, creatinine $1.17 \mathrm{mg} / \mathrm{dL}, \mathrm{Na}: 134 \mathrm{mmoL} / \mathrm{L}, \mathrm{K}$ : $5.63 \mathrm{mmoL} / \mathrm{L}$, and Cl: $109 \mathrm{mmoL} / \mathrm{L}$. An arterial blood gas (ABG) test showed $\mathrm{PaO}_{2}$ of $98 \mathrm{mmHg}, \mathrm{PaCO}_{2}$ of $28 \mathrm{mmHg}$, pH of $7.08, \mathrm{HCO}_{3}$ of $8.4 \mathrm{mmoL} / \mathrm{L}$, serum osmolality of $279 \mathrm{mmoL} / \mathrm{kg}$, base excess of -20 $\mathrm{mmoL} / \mathrm{L}$ and anion gap of $22,23 \mathrm{mEq} / \mathrm{L}$.

The patient was diagnosed with methanol intoxication and fluid and bicarbonate therapy was started immediately. The patient was hospitalized to the intensive care unit (ICU) after initial treatment in the ED. Formic acid was determined as $25.1 \mathrm{mg} / \mathrm{dL}$ (normal range 0-13 mg/dL) in urine. During hospitalization at the intensive care unit, proper fluid and bicarbonate treatment was continued, and there was no need for dialysis or additional treatment. An ophthalmology consultation was performed during his stay in the hospital, and no significant abnormalities were seen, thus a cranial computerized tomography (CT) was not performed. After 3 days follow-up, all the patient's complaints, including visual impairment, disappeared and the patient was discharged after being treated for three days. Informed consent was obtained from the patient.

\section{Discussion}

Methanol is converted to formaldehyde by alcohol dehydrogenase $(\mathrm{ADH})$ and the formaldehyde is converted to formic acid by aldehyde dehydrogenase in the liver. Formic acid is the main metabolite that is responsible for toxicity and metabolic acidosis caused by methanol intoxication. Formic acid causes metabolic acidosis and inhibits mitochondrial cytochrome c oxidase, which lead to tissue hypoxia. In the late phase of poisoning, lactate becomes more important when cellular aerobic respiration is blocked and anaerobic glycolysis and lactic acidosis develops $(5,6)$.

Methanol intoxication is a relatively rare but potentially serious medical emergency (7). The clinical presentation of methanol intoxication varies greatly from patient to patient. A latent period of 12-24 hours (until methanol is transformed to its toxic metabolites) often follows methanol ingestion and signs and symptoms may vary depending on the methanol intake path $(1,2)$. Most patients suffer from nausea, vomiting, headache, weakness, and visual loss, and changes in the affected areas may be seen in patients with dermal exposure (1). Large amounts of methanol ingestion may result in seizures, stupor, coma, and even death (2). The classical manifestations of methanol poisoning include visual disturbance (decrease in visual acuity, photophobia, reduction in light reflex, etc.), severe metabolic acidosis, and central nervous system (CNS) depression leading to respiratory failure (2).

The diagnosis of methanol intoxication is based on the presence of severe metabolic acidosis with a high anion and osmolar gap and high serum methanol levels (2). It has been reported in studies that metabolic acidosis and ocular injury develops when blood formic acid levels are above $20 \mathrm{mg} / \mathrm{dL}(5,8)$. The most common ocular findings are decreased visual acuity, reduction in light reflex, impaired color vision and visual field defects such as central, centrocecal, or peripheral scotoma. Acute fundus findings are optic disc hyperemia, nerve fiber edema at the disk borders and peripapillary retina, and retinal vein dilatation $(4,5,8)$. The acute period may end with complete recovery or in some cases optic atrophy may develop (4). İşcan et al. (4) reported a case of total bilateral optic nerve atrophy after the local application of methanol in a 54-year-old woman who wrapped her feet with methylated spirit-soaked materials for 6-7 $\mathrm{h}$ for pain relief and they concluded that even transdermal application of methanol can cause either death or optic atrophy. Our patient had metabolic acidosis with a high anion and osmolar gap and he also had decreased visual acuity during ED admission, however at his ophthalmology assessment on the $2^{\text {nd }}$ day of hospitalization he had normal visual acuity, and anterior and posterior segment examinations and pupillary light reflexes were normal for both eyes. The patient's formic acid level in urine was also measured to be high $(25.1 \mathrm{mg} / \mathrm{dL})$ during his ICU stay.

Methanol intoxication is generally seen after oral intake, but although rare, some cases of poisoning have been reported as a result of transdermal absorption (1-4). As in our case, especially when a history of oral methanol ingestion does not exist, diagnosis of methanol intoxication may be delayed $(2,3)$. Even if transdermal methanol poisoning seems rare, local application of methylated spirit is traditionally used for pain relief in some rural regions of Turkey (1-4). A diagnosis of methanol intoxication should be considered in patients with high anion gap metabolic acidosis who have visual symptoms and consciousness disturbances.

Recommended management of methanol intoxication includes supportive care, sodium bicarbonate to correct metabolic acidosis and to increase renal elimination of formic acid, antidotes such as a competitive ADH substrate (ethanol which has 20 times more affinity to $\mathrm{ADH}$ ) or $\mathrm{ADH}$ inhibitor (fomepizole) to block ADH metabolism of methanol, and dialysis to remove methanol and its toxic metabolites, to correct acidosis, and to shorten the course of hospitalization $(5,9)$. In our patient, metabolic acidosis was treated with bicarbonate both in ED and ICU, his clinical status improved quickly and he recovered without sequelae, no antidote treatment and dialysis was not performed.

\section{Conclusion}

It must be kept in mind that methanol can be absorbed through the skin and may rise to toxic levels in the blood rapidly. Transdermal methanol poisoning might be diagnosed late due to the absence of a history of oral intake. Emergency department physicians must consider methanol intoxication in patients of high anion gap metabolic acidosis with visual symptoms even if the patient has no history of oral intake.

Informed Consent: Written informed consent was obtained from patient who participated in this study. 
Peer-review: Externally peer-reviewed.

Author contributions: Concept - M.B., A.S.; Design - U.K., A.S.; Supervision M.B.; Resource - U.K., A.S.; Materials - U.K.; Data Collection and/or Processing - U.K., A.S.; Analysis and/or Interpretation - U.K., A.S., M.B.; Literature Search - U.K., A.S.; Writing - U.K., M.B.; Critical Reviews - M.B.

Conflict of Interest: No conflict of interest was declared by the authors.

Financial Disclosure: The authors declared that this study has received no financial support.

\section{References}

1. Gök E, Horoz M, Turgutalp K, Kıykım AA. Fatal Transdermal Methanol Intoxication: A Case Report and Review of Literature. Turkiye Klinikleri J Med Sci 2011; 31: 234-9. [CrossRef]

2. Karaduman F, Asil T, Balci K, Temizoz O, Unlu E, Yilmaz A, et al. Bilateral basal ganglionic lesions due to transdermal methanol intoxication. J Clin Neurosci 2009; 16: 1504-6. [CrossRef]
3. Soysal D, Yersal Kabayegit O, Yılmaz S, Tatar E, Ozatli T, Yildiz B, et al. Transdermal methanol intoxication: a case report. Acta Anesthesiol Scand 2007; 51: 779-80. [CrossRef]

4. İşcan Y, Coşkun Ç, Öner V, Türkçü FM, Taş M, Alakuş MF. Bilateral total optic atrophy due to transdermal methanol intoxication. Middle East Afr J Ophthalmol 2013; 20: 92-4. [CrossRef]

5. Tokgöz OS, Güney F, Kamış Ü, Paksoy Y. Bilateral putaminal and optical involvement after low dose of methanol exposure: case report. Erciyes Med J 2012; 34: 91-4. [CrossRef]

6. Liesivuori J, Savolainen H. Methanol and formic acid toxicity: biochemical mechanisms. Pharmacol Toxicol 1991; 69: 157-63. [CrossRef]

7. Anyfantakis D, Symvoulakis EK, Cristodoulakis EV, Frantzeskakis G. Ruling in the diagnosis of methanol intoxication in a young heavy drinker: a case report. J Med Life 2012; 5: 332-4.

8. Çelebi S, Aydemir O, Yılmaz T. Metil alkol intoksikasyonunda göz bulguları. MN Ophthalmology 2001; 8: 255-8

9. Mégarbane B. Treatment of patients with ethylene glycol or methanol poisoning: focus on fomepizole. Open Access Emerg Med 2010; 2: 6775. [CrossRef] 